\title{
Degradation of the performance of microchannel heat exchangers due to flow maldistribution
}

Nielsen, Kaspar Kirstein; Engelbrecht, Kurt; Christensen, Dennis ; Jensen, Jesper Buch; Smith, Anders; Bahl, Christian

Published in:

Applied Thermal Engineering

Link to article, DOI:

10.1016/j.applthermaleng.2012.02.019

Publication date:

2012

Link back to DTU Orbit

Citation (APA):

Nielsen, K. K., Engelbrecht, K., Christensen, D., Jensen, J. B., Smith, A., \& Bahl, C. (2012). Degradation of the performance of microchannel heat exchangers due to flow maldistribution. Applied Thermal Engineering, 40, 236-247. https://doi.org/10.1016/j.applthermaleng.2012.02.019

\section{General rights}

Copyright and moral rights for the publications made accessible in the public portal are retained by the authors and/or other copyright owners and it is a condition of accessing publications that users recognise and abide by the legal requirements associated with these rights.

- Users may download and print one copy of any publication from the public portal for the purpose of private study or research.

- You may not further distribute the material or use it for any profit-making activity or commercial gain

- You may freely distribute the URL identifying the publication in the public portal 


\title{
Degradation of the performance of microchannel heat exchangers due to flow maldistribution
}

\author{
K.K. Nielsen ${ }^{1}$, K. Engelbrecht ${ }^{1}$, D.V. Christensen ${ }^{1,2}$, J.B. Jensen ${ }^{1}$ A. \\ Smith $^{1}$, C.R.H. Bahl ${ }^{1}$ \\ ${ }^{1}$ Fuel Cells and Solid State Chemistry Division \\ Risø National Laboratory for Sustainable Energy \\ Technical University of Denmark \\ Frederiksborgvej 399, DK-4000 Roskilde, Denmark \\ ${ }^{2}$ Niels Bohr Institute, University of Copenhagen \\ Blegdamsvej 17, DK-2100 Copenhagen, Denmark
}

\begin{abstract}
The effect of flow maldistribution on the performance of microchannel parallel plate heat exchangers is investigated using an established single blow numerical model and cyclic steady-state regenerator experiments. It is found that as the variation of the individual channel thickness in a particular stack (heat exchanger) increases the actual performance of the heat exchanger decreases significantly, deviating from the expected nominal performance. We show that this is due to both the varying fluid flow velocities in each individual channel and the thermal cross talk between the channels transverse to the direction of the flow.
\end{abstract}

Keywords: microchannels, flow maldistribution, thermal crosstalk, parallel plates 


\section{Introduction}

Microchannel heat exchangers show promise of theoretically large heat transfer coefficients and provide the ability to design compact devices. These are two very central parameters in the areas of, e.g., cryocoolers, dehumidifiers, Stirling engines, solar power, electronics cooling and magnetic refrigeration $[1,2,3,4,5,6,7]$.

Parallel plate heat exchangers are considered, from a theoretical standpoint, to have a good ratio between heat transfer properties and pressure drop. In order to reach sufficient values of the number of transfer units $(N T U)$ and heat transfer coefficient, $h$, the flow channels defined by the parallel plates, or similar geometries, must be made into the sub-millimeter regime. This is due to the fact that, assuming a constant Nusselt number, the only parameter that can increase $h$ is a decrease in the hydraulic diameter, $d_{h}$. The required flow rate, specified through operating frequency and thermal utilization of the heat exchanger, defines a minimum value of $h$ and thus $d_{h}$ for a given value of the $N T U$. In many applications it is therefore important to have quite small channels (hydraulic diameters down to or even below $100 \mu \mathrm{m}$ are not unrealistic for many applications) [8].

The range of hydraulic diameters from $1 \mu \mathrm{m}$ to $1 \mathrm{~mm}$ is commonly defined as microchannels [9]. Significant discrepancies are, however, often observed between experiments and theory in this range. This has led to a quite significant amount of research into various aspects of the governing physics at the relevant scales. 


\subsection{Relevant physical effects at the microscale level}

Several explanations for the relatively large deviations of the predicted heat transfer performance and that experimentally observed on the microscale have been suggested. These include physical effects not previously considered such as, e.g., whether the continuum assumption breaks down, the influence of surface roughness in the channels etc. In Ref. [9] these issues are reviewed and it is concluded that for incompressible laminar flows with aqueous fluids no new physical phenomena happen in microchannels. This is supported by careful experiments performed on single-channel tubes and square channel heat exchangers in the microchannel range $[9,10,11]$.

A range of assumptions are usually made in order to model the coupled fluid-flow and heat transfer problem in heat exchangers in general. These issues are discussed in great detail in [9] and references therein. Here, they are summarized:

- Entrance effects

- Temperature dependent properties

- Viscous dissipation

- Surface roughness

- Conjugate heat transfer

- Uneven flow distribution in flow manifolds

The entrance effects cover both hydrodynamic and thermal issues. It is important to investigate whether the flow may be considered fully developed 
and, in the case of a 1D model, also whether the thermal entrance length is relatively short.

Temperature dependent properties may influence the performance in several ways. If the viscosity of the heat transfer fluid varies significantly then the pressure drop in an actual experiment may be somewhat different than predicted. Similarly, if the specific heat and the mass density are sensitive to temperature then that may cause substantial deviations between the results observed experimentally and those predicted by a numerical model neglecting these effects.

The viscous dissipation is the irreversible conversion of mechanical energy to heat in the fluid due to the pressure drop. If this effect is considerable and not taken into account in a numerical model, then the heat transfer will be incorrectly predicted. A general criterium for estimating the importance of viscous dissipation is to calculate the pressure drop and use that to find the associated energy release. Comparing this number to the total amount of transferred heat in the system is a good estimate of the possible importance of the viscous heating.

The surface roughness is indeed difficult to model precisely. Several investigations have shown, however, that the impact of surface roughness on the heat transfer effectiveness may be either positive or negative depending on the characteristics of the roughness $[12,13,14]$. It is generally concluded that surface roughness increases the pressure drop [9].

The issue of conjugate heat transfer is the effect of thermal conduction in the flow direction in the heat exchanger solid. For small Reynolds numbers this effect may be quite significant and using simple Nusselt-Reynolds 
correlations may not sufficiently describe the actual heat transfer $[9,11,15]$.

Finally, in a microchannel heat exchanger with multiple channels, flow maldistribution in the channels can be significant. If the channels are nominally small their spacing may be manufactured with a relatively large uncertainty. The resulting performance of the heat exchanger is difficult or even impossible to predict without the help of a numerical model resolving the heat transfer problem in at least two dimensions.

While much research on heat transfer and fluid flow modeling in microchannels generally studies a single channel [16, 17], entire microchannel heat exchangers with practical manufacturing tolerances have received less attention. How fluid maldistribution in microchannel manifolds affects heat transfer performance was studied using a 3D model [18]. A 1D heat exchanger model was used to predict how flow maldistribution affects vapor compression system performance $[19,20]$. This method predicts that two individual plate stacks with different spacing will have poorer heat transfer performance than an equivalent stack with average plate spacing of the two. The performance of heterogeneous beds was estimated in various limiting cases for bundled parallel capillaries in Ref. [21]. Here, it was concluded that the effect of size variations of the capillary diameter generally reduces the performance. Flow and temperature distribution in parallel channels were studied numerically when obstructions such as bubbles or debris were placed in one of the channels [22]. The outlet temperature profile was shown to be affected by obstruction in one of the channels, but the change in heat transfer performance was not quantified.

However, the parallel heat exchanger approach cannot capture the effect 
of thermal interactions (cross talk) between adjacent fluid channels with different channel heights. The effect of this so-called cross talk on microchannel stack performance is not well understood.

In this paper we investigate the influence of flow maldistribution and the associated conjugate heat transfer using the 2-dimensional heat transfer and fluid flow model presented in Ref. [23, 24] on four custom made parallelplate heat exchanger stacks built from commercial aluminum sheets. The four stacks all have the same plate thickness of $0.4 \mathrm{~mm}$ and number of plates but different nominal plate spacings ranging from 0.1 to $0.7 \mathrm{~mm}$. The performance as passive thermal regenerators is investigated experimentally in a setup that allows a periodic flow in the system, and the performance is evaluated at cyclic steady state.

The numerical model simulates a single-blow process in a given inhomogeneous stack of parallel plates. The single-blow technique is commonly used experimentally to determine heat transfer coefficients in difficult heat exchanger geometries such as packed beds. In this work the technique is performed numerically to assess the bulk heat transfer in a flat plate regenerator with inhomogeneous plate spacing. The reduction in heat transfer coefficient due to the inhomogeneity of the stack is determined through comparison with the ideal single channel case (which is completely equivalent to a homogeneous stack of any number of plates). This reduction factor is found at varying flow rates in order to probe the influence of flow maldistribution as a function of Reynolds number.

The four regenerators are tested under various operating conditions in the test device described below. The regenerators are subjected to a periodic fluid 


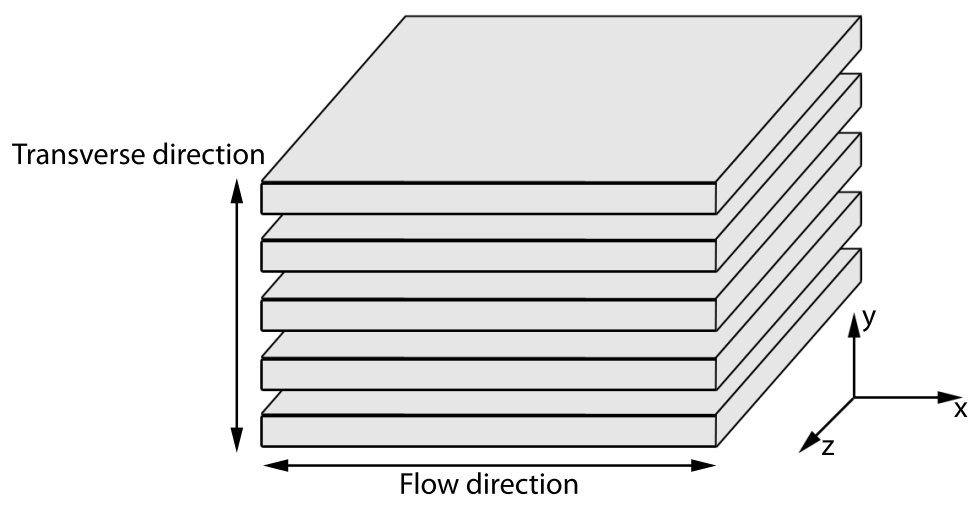

Figure 1: Coordinate system describing the stacking of the flat plates.

flow and a cyclic steady-state temperature span is thus achieved. A larger temperature span implies a larger heat transfer coefficient when comparing different stacks under otherwise the same conditions. In this way the model and experimental results may be compared in terms of the trends predicted by the two approaches, respectively.

\section{Experimental}

\subsection{Construction of aluminum regenerators}

The flat plate stacks were fabricated from $0.4 \mathrm{~mm}$ thick commercial grade $\mathrm{Al}$ plates that were laser cut to the dimensions $40 \times 25 \mathrm{~mm}^{2}$. Thin wires were used as spacers to regulate the plate spacing. Each stack was made with two wires sandwiched between each plate in a simple rig to facilitate easy plate stacking. After all the plates were stacked, the stack was compressed slightly to reduce the effects of slight bending of the wires and the plates were bonded with epoxy on both sides along the entire length of the plates in the flow direction $(40 \mathrm{~mm})$. The stacks were placed in nylon housings and sealed 
around the periphery of the stack with silicone to prevent heat transfer fluid from bypassing the stack. The fabrication and test procedure for the stacks is discussed in more detail in Ref. [25, 26].

A Vantage Laser Scanner was used to scan the cross sections at both ends (fluid inlet and outlet) of each stack. The resolution along the direction of the stacking of the aluminum plates was set to $5 \mu \mathrm{m}$ and along the transverse direction it was set to $20 \mu \mathrm{m}$ (the $y z$-plane in Fig. 1). The laser scanner is designed to measure surface topology. However, in this case the data from the scanner was truncated to two values; one representing solid aluminum, the other representing void space, i.e. flow channels. In this way the channel and plate thicknesses were found through analyzing the 2-dimensional maps of the cross section at either ends of the stacks. The processed maps of each stack configuration are shown in Fig. A.12 in Appendix A. Arbitrarily the two cross sections for each stack are denoted "face 1" and "face 2", respectively.

The distance between each plate in each stack configuration is found for each measured point along the $z$-direction (see Fig. 1). From these, the mean and standard deviation values for each channel are found. In Tab. I the values are provided for each stack. The standard deviations on the thicknesses of the plates are more than an order of magnitude smaller than the channel spacings and it may therefore be safely assumed that the plates are homogeneous and identical.

From Tab. I it is seen that the standard deviation actually decreases as the nominal plate spacing decreases. However, the difference is within a factor of two for a change in nominal spacing of more than a factor of 
Table I: Summary of the nominal plate spacing, the actually measured mean plate spacing $(\mu)$, the absolute standard deviation $(\sigma)$, the relative standard deviation and the maximum and minimum channel spacings. Measurements are given for both face 1 and face 2 of the stack.

\begin{tabular}{c|cccc} 
Nom. sep. $[\mathrm{mm}]$ & $\mu[\mathrm{mm}]$ & $\sigma[\mathrm{mm}]$ & Min.sep.[mm] & Max.sep. $[\mathrm{mm}]$ \\
\hline $0.7(1)$ & 0.743 & 0.046 & 0.631 & 0.815 \\
$0.7(2)$ & 0.755 & 0.043 & 0.694 & 0.852 \\
$0.4(1)$ & 0.407 & 0.053 & 0.310 & 0.496 \\
$0.4(2)$ & 0.415 & 0.036 & 0.353 & 0.484 \\
$0.2(1)$ & 0.211 & 0.026 & 0.161 & 0.263 \\
$0.2(2)$ & 0.214 & 0.027 & 0.186 & 0.263 \\
$0.1(1)$ & 0.116 & 0.027 & 0.044 & 0.159 \\
$0.1(2)$ & 0.112 & 0.028 & 0.053 & 0.191 \\
\hline
\end{tabular}

seven. The relative standard deviation, therefore, shows a clear increase as the nominal plate spacing decreases. The stack with a nominal spacing of 0.1 $\mathrm{mm}$ has a standard deviation of the plate spacings of $24 \%$ whereas the stack with a nominal spacing of $0.7 \mathrm{~mm}$ has a standard deviation of approximately $6 \%$.

\subsection{Periodic flow test machine setup}

A modular device built originally for use as an active magnetic regenerator test machine [27] is used to test the stacks as passive thermal regenerators; see Fig. 2 for details. A reciprocating piston provides oscillating flow through the regenerator between the hot and cold thermal reservoirs while a heater maintains a temperature difference between the reservoirs. The device and passive regenerator experiments are described in more detail in Ref. [26]. It has been modified slightly for the experiments presented here. The heater location has been moved from the face of the piston to a fixed location near the regenerator inlet. A mesh screen was also added to the ends of the regenerators in order to achieve a better flow distribution in the regenerators and 


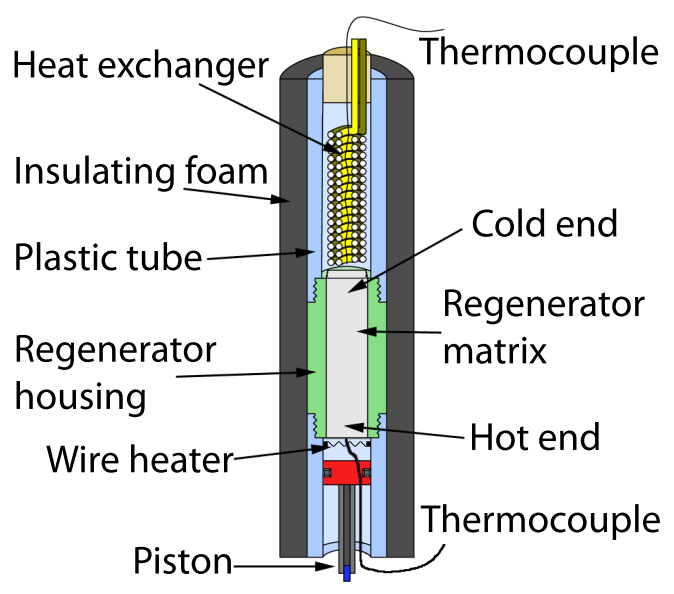

Figure 2: Schematic of the test machine used for the passive regenerator experiments. The details about the device are published in Refs. [27, 26].

more even fluid inlet temperature. When operated as a passive regenerator the end with the piston (and heater) is thus the hot end, whereas the end with the constant-temperature heat exchanger is the cold end. The temperature is measured by type E thermocouples at both ends. A heater power and oscillating fluid flow are applied to each regenerator and the resulting cyclic steady-state temperature span is measured. Higher temperature spans correspond to higher regenerator effectiveness and thus to better heat transfer performance in the regenerator [28].

\section{Numerical analysis}

One major goal of this paper is to demonstrate the effect on bulk heat transfer in a microchannel heat exchanger or regenerator caused only by nonuniform channel spacing by numerical modeling. The work here is based on a CFD model of a stack of plates with varying channels reported in Ref. [23]. In the model the following assumptions are made: 
- the fluid is aqueous with properties assumed temperature-independent

- the fluid flow is single phase, incompressible, laminar and fully developed

- the fluid at the inlet and outlet of the heat exchanger has a constant pressure and a well-distributed flow

- the heat exchanger inlet and outlet are adiabatic

- the fluid and solid do not interact thermally with the ambient or the heat exchanger housing

- viscous dissipation of pump power inside the heat exchanger is negligible

- each solid plate is flat with uniform thickness and no roughness

- each fluid channel is uniform in the flow direction but the height of each flow channel can vary

- perfect fluid mixing at the heat exchanger outlet

According to Ref. [29] it is valid to treat fluid in channels with the heights considered here as a continuum. Applying finite element analysis of fluid and heat transfer phenomena to microchannel heat exchangers has previously been shown to produce accurate results [30]. Viscous dissipation effects become more significant as channel spacing is reduced and the fluid flow rate is increased. For the cases considered, the maximum pumping loss represents $0.5 \%$ of the energy transferred during the simulated blow process and is therefore assumed to have minimal effects on the predicted results. 


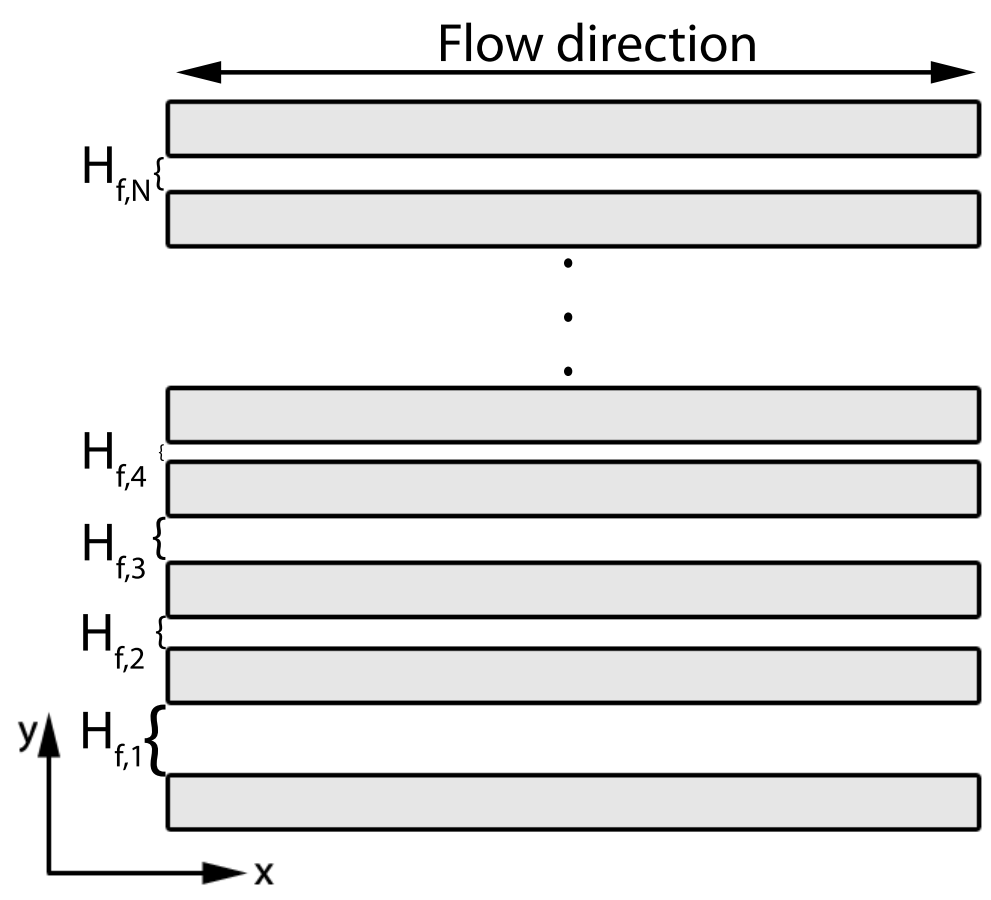

Figure 3: The coordinate system of the numerical model. The different channel thicknesses are indicated in the figure to have varying thickness. It is important to stress that along the $x$-direction, the channel heights do not change.

A method to determine when conjugate heat transfer cannot be neglected is to calculate the Maranzana number [31]

$$
\mathrm{Ma}=\frac{k_{\mathrm{s}} A_{\mathrm{s}}}{k_{\mathrm{f}} A_{\mathrm{f}} \operatorname{RePr}}
$$

where Re is the Reynolds number, Pr is the Prandtl number, $k$ is the thermal conductivity, $A$ is surface area and the subscripts s and $\mathrm{f}$ refer to solid and fluid, respectively. For conditions in this study, Ma is generally of the order of 5 . Values of less than 0.01 correspond to situations where conjugate heat transfer can be ignored, thus conduction along the aluminum plates cannot be ignored and heat transfer is modeled in both the $x$ - and $y$-direction (see 
Fig. 3)

\subsection{Numerical model}

The numerical model is comprised of a number of identical plates separated by fluid channels with varying spacing and has been implemented in the commercial software package Comsol [32]. The fluid and solid in the heat exchanger are initialized with a uniform low temperature and the bed is subjected to a step increase in fluid temperature and fluid flow at the beginning of the simulation. This numerical heat transfer model, presented and validated in Ref. [23], is used to predict the performance of each microchannel stack, with channel thicknesses corresponding to the laser measurements presented above, and to compare the performance to that of ideal stacks of uniform fluid channels. Each cross section measured with the laser scanner is assumed to represent an independent heat exchanger that maintains the specific cross section along the entire length of the stack, i.e. the individual channels have constant thickness throughout the stack. In this way, a total of eight heat exchangers are investigated, as each set of nominal channel thickness, stacks denoted by "face 1" and "face 2", respectively, are individually analyzed. It is expected that each pair will perform somewhat similarly, however, as the data presented in Appendix A indicate, the "face 1" and "face 2" of the stacks are not completely identical.

Since laser measurements could not be obtained for each flow channel, the number of channels used in the numerical model is different than the number in the experimental stack. Here, the number of channels in the numerical model is the same as the number of channels that could be measured with the laser technique, which is 17 channels for the $0.7 \mathrm{~mm}$ spacing, 14 channels 
for the $0.4 \mathrm{~mm}$ spacing, 15 channels for the $0.2 \mathrm{~mm}$ spacing, and 17 channels for the $0.1 \mathrm{~mm}$ spacing stacks, respectively.

The model solves the coupled 2-dimensional transient heat transfer equations of both the solid and heat transfer fluid with the resolved dimensions being the direction of the flow (denoted $x$ ) and the direction of the stacking of the plates (denoted $y$; see Fig. 3). Therefore, the microchannels are treated as infinitely wide parallel plates (the $z$-direction in Fig. 1 is not modeled). The governing heat transfer equations in the fluid and solid are

$$
\begin{aligned}
\rho_{\mathrm{f}} c_{\mathrm{f}}\left(\frac{\partial T_{\mathrm{f}}}{\partial t}+\mathbf{u} \cdot \nabla T_{\mathrm{f}}\right) & =k_{\mathrm{f}} \nabla^{2} T_{\mathrm{f}} \\
\rho_{\mathrm{s}} c_{\mathrm{s}} \frac{\partial T_{\mathrm{s}}}{\partial t} & =k_{\mathrm{s}} \nabla^{2} T_{\mathrm{s}} .
\end{aligned}
$$

Here, $T$ is temperature and $t$ is time. The mass density, specific heat and thermal conductivity, denoted $\rho, c$ and $k$, respectively, are assumed constant at all times and temperatures.

The heat transfer equations, (2-3), are coupled at the boundary interfaces between the solid and the fluid domains through the boundary condition

$$
k_{\mathrm{s}} \frac{\partial T_{\mathrm{s}}}{\partial y}=k_{\mathrm{f}} \frac{\partial T_{\mathrm{f}}}{\partial y}
$$

valid on the internal boundaries only. In this way the non-slip boundary condition is implicitly assumed and, furthermore, no temperature jumps are assumed at the boundaries between solid and fluid.

\subsection{Fluid flow velocity}

The fluid flow, represented by the velocity field, $\mathbf{u}$, is assumed to be laminar, incompressible and fully developed. The velocity field thus reduces 
to

$$
\mathbf{u}=\left(u_{x}(y), 0,0\right)
$$

The velocity profile in the $i$ th channel, $u_{x, i}(y)$, is then found analytically,

$$
u_{x, i}(y)=\frac{3}{2} \tilde{u}_{i}\left(1-4 \frac{\left(y-H_{\mathrm{f}, i} / 2\right)^{2}}{H_{\mathrm{f}, i}^{2}}\right),
$$

where $H_{\mathrm{f}, i}$ is the height of the $i$ th fluid channel and $y_{i}$ is the $i$ th coordinate in the $y$-direction being zero at the boundary between the fluid channel and the lower plate and equal to $H_{\mathrm{f}, i}$ at the corresponding boundary between the upper plate and the fluid channel. The mean fluid velocity in the $i$ th channel is denoted $\tilde{u}_{i}$.

The pressure drop in the $i$ th channel may be found analytically [33]:

$$
\begin{aligned}
\Delta p_{i} & =\frac{96}{\operatorname{Re}_{i}} \frac{\rho_{\mathrm{f}} L \tilde{u}_{i}^{2}}{2 d_{h, i}} \\
& =12 \frac{L \mu_{\mathrm{f}} \tilde{u}_{i}}{H_{\mathrm{f}, i}^{2}}
\end{aligned}
$$

where $\operatorname{Re}_{i}=\frac{\rho_{\mathrm{f}} d_{h, i} \tilde{u}_{i}}{\mu_{\mathrm{f}}}$ is the Reynolds number $\left(d_{h, i}=2 H_{\mathrm{f}, i}\right.$ is the hydraulic diameter of the $i$ th channel and $\mu_{\mathrm{f}}$ is the viscosity of the fluid) and $L$ is the length of the channel.

The total volumetric flow rate per unit width of the stack is

$$
\dot{V}^{\prime}=\sum_{i}^{N} \dot{V}_{i}^{\prime}=\sum_{i}^{N} \tilde{u}_{i} H_{\mathrm{f}, i}
$$

where $N$ is the number of channels. Combining Eqs. 7 and 8 and assuming 
that the pressure drop across each individual channel is the same results in

$$
\tilde{u}_{i}=\dot{V}^{\prime} \frac{H_{\mathrm{f}, i}^{2}}{\sum_{i=1}^{N} H_{\mathrm{f}, i}^{3}} .
$$

The transient equations governing heat transfer in the microchannels (Eq. 2 - 4) are solved over a finite element grid using the commercial software package Comsol. Details about the mesh parameters and solver package used for the numerical analysis are given in Table. II. The hot fluid is allowed to flow through the heat exchanger until the temperature at the heat exchanger outlet is within $0.005 \mathrm{~K}$ of the inlet temperature. The blow time depends on fluid flow rate and channel spacing.

\subsection{Evaluating the performance of the parallel plate heat exchangers}

Single blow testing has previously been used to experimentally measure the heat transfer in heat exchangers with complex geometries, such as packed particles, where direct measurement of the heat transfer coefficient is difficult. The single blow method described in, e.g., [34] measures the thermal response of a heat exchanger subjected to a step change in inlet temperature. If the inlet condition is well known, the outlet temperature profile measured as a function of time can be used to determine the average heat transfer in the heat exchanger. Some of the advantages of treating the entire plate stack using a single blow method are that it characterizes the heat transfer in the entire heat exchanger, rather than each flow channel individually, and that it allows for the interaction between channels of different heights to influence overall heat transfer performance.

The thermal response of a heat exchanger made of a distribution of nonuniform channels subjected to a step change of fluid flow and temperature at 
Table II: Parameters used to run the single blow heat exchanger model.

\begin{tabular}{cc}
\hline Parameter & Value \\
\hline Number of fluid channels & $14-17$ \\
\hline Plate length & $40 \mathrm{~mm}$ \\
\hline Plate thickness & $0.4 \mathrm{~mm}$ \\
\hline Plate specific heat & $903 \mathrm{~J} / \mathrm{kgK}$ \\
\hline Plate thermal conductivity & $235 \mathrm{~W} / \mathrm{mK}$ \\
\hline Plate density & $2704 \mathrm{~kg} / \mathrm{m}^{3}$ \\
\hline Fluid specific heat & $4200 \mathrm{~kg} / \mathrm{m}^{3}$ \\
\hline Fluid thermal conductivity & $0.6 \mathrm{~W} / \mathrm{mK}^{3}$ \\
\hline Fluid density & $1000 \mathrm{~kg} / \mathrm{m}^{3}$ \\
\hline Mass of aluminum plates & $0.0195 \mathrm{~kg}$ \\
\hline Number of vertical elements in each channel & 128 \\
\hline Number of vertical elements in each plate & 8 \\
\hline Maximum time step & 0.005 \\
\hline Solver package & $\mathrm{UMFPack}$ \\
\hline Solver absolute tolerance & 0.001 \\
\hline Solver relative tolerance & 0.0001 \\
\hline
\end{tabular}

the inlet is modeled. The bulk average outlet temperature is calculated and used to characterize the average heat transfer in the heat exchanger using the same standard techniques applied in single blow experiments.

Characterizing the performance of a specific parallel plate stack exposed to certain conditions may be done in several ways. Fundamentally, as the flow propagates through the heat exchanger the temperature of the fluid at the output, $T_{\mathrm{o}, \mathrm{f}}$, changes from the initial temperature, $T_{\mathrm{i}}$, until it eventually reaches the fluid inlet temperature, $T_{\mathrm{i}, \mathrm{f}} . \quad T_{\mathrm{o}, \mathrm{f}}(t)$ is defined as the average temperature at time $t$ at the outlet of the flow channel. The total volumetric 
average value, assuming a constant specific heat, is equal to

$$
T_{\mathrm{o}, \mathrm{f}}(t)=\frac{\sum_{i=1}^{N} T_{\mathrm{o}, \mathrm{f}, i}(t) \tilde{u}_{i} H_{\mathrm{f}, i}}{\sum_{i=1}^{N} \tilde{u}_{i} H_{\mathrm{f}, i}},
$$

where $T_{\mathrm{o}, \mathrm{f}, i}(t)$ is the average outlet temperature of the $i$ th channel at time $t$.

This temperature response curve is key to understanding the heat transfer performance; however, it is not a direct measurement of the heat transfer performance in the heat exchanger. In Ref. [34] a set of experimental techniques to evaluate the regenerator performance using this curve is discussed. The methods are focused on various properties of the temperature response curve and each has its own justification, depending on the experimental conditions. For this work, it was decided to consider two of the methods. These are denoted the M and S methods, respectively. The former is focused on the steepest gradient of the temperature response curve and the latter considers the difference in time between the breakthrough of 20 and $80 \%$ of the temperature curve, respectively. Figure 4 gives a graphical explanation of the $\mathrm{S}$ and $\mathrm{M}$ values for a certain temperature breakthrough curve.

The "M method" may mathematically be written as [34]

$$
\mathrm{M}=K_{\max }\left(\frac{\mathrm{d} T_{\mathrm{o}, \mathrm{f}}}{\mathrm{d} t}\right) .
$$

Here $K$ is a function of the volumetric flow rate and the thermal properties.

The "S-method" may be written as

$$
\mathrm{S}=C\left(\tau_{80}-\tau_{20}\right)
$$

where $C$ is again a function of the volumetric flow rate and the thermal properties of the solid and fluid. $\tau_{20}$ and $\tau_{80}$ mark the 20 and $80 \%$ breakthrough 


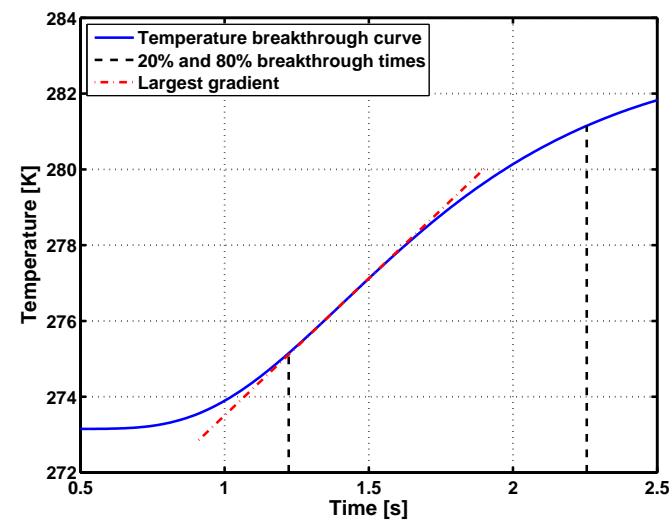

(a)

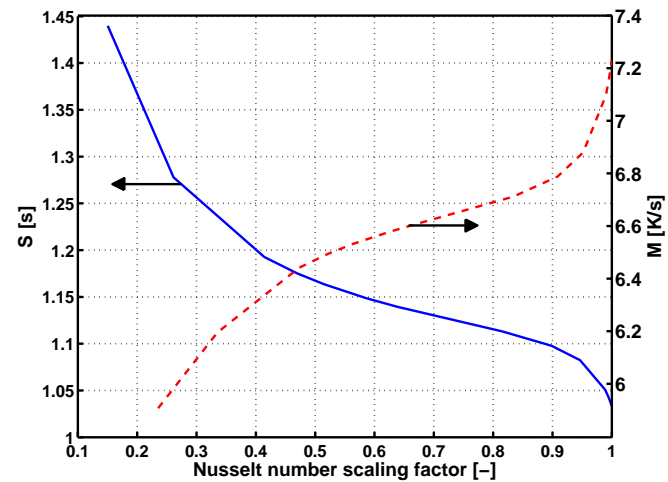

(b)

Figure 4: Left: the $\mathrm{S}$ and $\mathrm{M}$ methods explained in terms of a temperature break through curve. The S-method is based on the time difference between the breakthroughs at 20 and $80 \%$, respectively. The M-method is based on the largest gradient of the breakthrough curve. Right: example of the $\mathrm{M}$ and $\mathrm{S}$ values as a function of Nusselt number reduction factor. Both figures are from the single-channel model with a a volumetric flow rate of $9 \mathrm{~mm}^{2} \mathrm{~s}^{-1}$ and a channel thickness of $0.2 \mathrm{~mm}$.

times of the outlet curve, $T_{\mathrm{o}, \mathrm{f}}(t)$ (see Fig. 4(b)).

To determine the average heat transfer in the heat exchanger, the values of $\mathrm{M}$ and $\mathrm{S}$ must be matched to the corresponding values of an output curve for a heat exchanger with known heat transfer characteristics. The known geometry chosen in this work is a single uniform channel with a half plate at either side made from the same materials as the multiple plate heat exchanger. A single microchannel has been shown experimentally to agree with its theoretical performance [11] and experiences nominally the same conjugate heat transfer as a microchannel stack with varying channel heights, making it a good benchmark condition for fitting $\mathrm{M}$ and $\mathrm{S}$ values.

Fitting the output curves of the full non-uniform stack presents a challenge. Conjugate heat transfer can become significant due to the high conductivity of the solid and the shape of the outlet fluid curve for both the 
single and multiple channel models can be sensitive to a range of modeling parameters. Four modeling scenarios in which the heat transfer between solid and fluid can be varied were considered for fitting $\mathrm{M}$ and $\mathrm{S}$ values:

- a 1D regenerator model with a user-specified heat transfer coefficient

- a 2D model of a single channel with varying plate spacing

- a 2D model of a single channel with varying fluid thermal conductivity

- a 2D model of a single channel with a varying thermal resistance between the solid and fluid boundaries.

The 1D model (published in Ref. [35]) did not provide adequate results because the axial conduction in the $1 \mathrm{D}$ and $2 \mathrm{D}$ models seemed to affect the model results in different ways. The 1D model ignores temperature gradients normal to the fluid flow direction in the solid and fluid as well as the velocity profile in the fluid, which likely caused small discrepancies between the two models under certain operating conditions.

Using a 2D model and altering the plate spacing to vary the heat transfer has the disadvantage that changing the plate spacing also changes the porosity of the stack and thus the average fluid velocity in the channel, thus changing several transport properties in the heat exchanger.

Using a 2D model and varying the fluid thermal conductivity effectively varies the heat transfer in the regenerator, but it also changes the rate in which heat is transferred from the fluid at the wall into the bulk fluid stream. This also artificially changes thermal transport in the fluid, making it nonideal for a fitting model. 
Adding a thermal resistance between the fluid and solid domains in a 2D model allows the effective heat transfer between the solid and fluid to vary while preserving the same regenerator geometry and heat transfer in both domains. Therefore, all curve fitting was done using the thermal resistance method.

\subsection{Convective heat transfer coefficient}

The convective heat transfer coefficient may be found from the Nusselt number relation.

$$
h=\frac{\mathrm{Nu} k_{\mathrm{f}}}{d_{h}},
$$

The mean Nusselt number for a parallel plate duct at constant wall temperature varies along the flow direction [36]; however, for the operating conditions considered here the average Nusselt number varies less than $1 \%$ over the range of flow rates and channel thicknesses. In order to illuminate the impact of flow maldistribution on the heat transfer performance of the parallel plate heat exchanger $h$ is calculated based on the constant Nusselt number, $7.54[36,37]$.

The single channel model is, of course, run at the average channel height of the multiple channel model. The thermal resistance acts as a reduction in the heat transfer coefficient between the fluid and solid. This may be formulated mathematically as a Nusselt number scaling factor

$$
\mathrm{Nu}_{\mathrm{scl}}=\frac{1 / h}{1 / h+d / k}
$$

where $d$ is the thickness of the virtual thermal resistance layer and $k$ is the conductivity. Figure 5 gives an examples of the influence that the thermal 
resistance layer has on the breakthrough curve.

$\mathrm{M}$ and $\mathrm{S}$ can then be found as a function of the Nusselt number scaling factor in the heat exchanger by varying the thermal resistance in the single channel model and deriving them from the temperature breakthrough curves. An example of this is given in Fig. 4. The single channel model (with two half plates - one on either side) is equivalent to a homogeneous stack of any number of plates.

In this way, the average heat transfer in a stack of varying microchannels can be summarized as having the same heat transfer performance as a homogeneous stack having a reduced effective heat transfer coefficient yielding the same value of $\mathrm{M}$ or $\mathrm{S}$. In order to compare $\mathrm{M}$ and $\mathrm{S}$ values for the single channel and multiple channel heat exchangers, the average fluid flow per channel must be equal. Note that larger channels in the multiple channel heat exchangers will have a larger fluid flow rate than the smaller channels (since they experience the same pressure drop). The average channel fluid flow, however, must be the same as the single channel heat exchanger in the multiple channel heat exchanger .

The curves for $\mathrm{M}\left(\dot{V}_{0}^{\prime}, \mathrm{Nu}_{\mathrm{scl}}, H_{\mathrm{f}}\right)$ and $\mathrm{S}\left(\dot{V}_{0}^{\prime}, \mathrm{Nu}_{\mathrm{scl}}, H_{\mathrm{f}}\right)$ may thus be found at a given volumetric flow rate, $\dot{V}_{0}^{\prime}$, and nominal plate spacing, $H_{\mathrm{f}}$. In order to quantify the performance of an inhomogeneous regenerator, the values of $\mathrm{M}_{\text {reg }}$ and $\mathrm{S}_{\text {reg }}$ are extracted from the breakthrough temperature curve of that particular regenerator (and at $\dot{V}_{0}^{\prime}$ ). The Nusselt number scaling factor is then found through interpolation in the $\mathrm{M}\left(\dot{V}_{0}^{\prime}, \mathrm{Nu}_{\mathrm{scl}}, H_{\mathrm{f}}\right)$ and $\mathrm{S}\left(\dot{V}_{0}^{\prime}, \mathrm{Nu}_{\mathrm{scl}}, H_{\mathrm{f}}\right)$ single channel data, respectively. The effective heat transfer coefficient may 


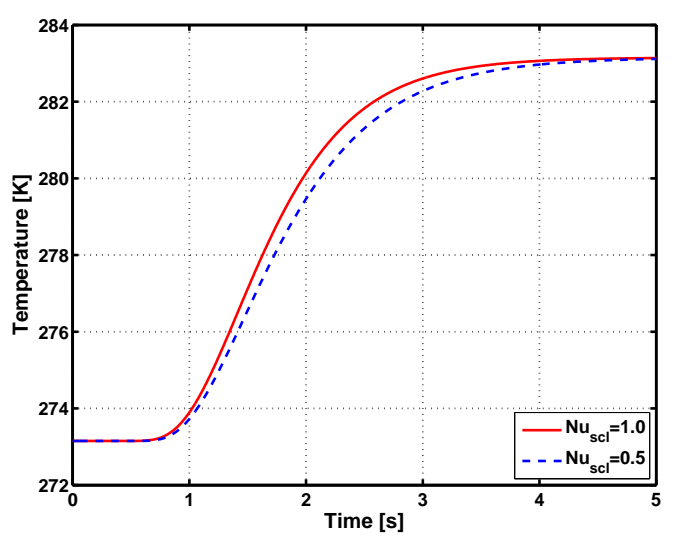

Figure 5: The influence of thermal resistance on the temperature breakthrough curves. $\mathrm{An} \mathrm{Nu}_{\mathrm{scl}}=1.0$ corresponds to no thermal resistance between the solid and fluid.

then be found as

$$
h_{\mathrm{eff}}=\mathrm{Nu}_{\mathrm{scl}} \frac{7.54 k_{\mathrm{f}}}{d_{h}}
$$

The Nusselt number scaling factor determined from the $\mathrm{M}$ and $\mathrm{S}$ values, respectively, were found to agree.

\section{Results and discussion}

\subsection{Experimental results}

The aluminum regenerator experiments were designed to compare model predictions with experimental results. For a passive regenerator with constant material properties, the regenerator effectiveness is a function of utilization and $N T U$ [28]. When the fluid flow rate and the mass of the solid heat exchanger material are held constant, the only factor that affects regenerator effectiveness is the heat transfer coefficient between the solid and the fluid, which is directly proportional to the $N T U$. Therefore, a higher effective heat transfer coefficient will result in a more effective regenerator. 
The four aluminum stacks discussed in detail above were tested in the active magnetic regenerator test device described in Sec. 2.2 as passive regenerators. For each stack two flow rates and four different values of the thermal utilization were tested. The thermal utilization is defined as

$$
\varphi=\frac{\dot{m} c_{\mathrm{f}}}{2 f c_{\mathrm{s}} m_{\mathrm{s}}}
$$

where $\dot{m}$ is the fluid mass flow rate, $f$ is operating frequency and $m_{\mathrm{s}}$ denotes the mass of solid material.

Figure 6 gives the results in the form of steady-state temperature spans as a function of the nominal channel thickness at a fixed heater power of $2.1 \mathrm{~W}$. If each regenerator were fabricated with uniform plate spacing, it would be expected that the regenerator temperature span should increase as the plate spacing decreases. However, for the non-uniform regenerators tested here, the stack nominally spaced with $0.2 \mathrm{~mm}$ has the best performance, indicating the largest effective heat transfer coefficient in this regenerator in all cases. The performances of the $0.1 \mathrm{~mm}$ and $0.4 \mathrm{~mm}$ stacks are quite similar with a tendency that the $0.4 \mathrm{~mm}$ stack performs slightly better than the $0.1 \mathrm{~mm}$. The $0.7 \mathrm{~mm}$ stack has overall the poorest performance. The experimental performance suggests a severe reduction in the heat transfer coefficient from the expected values as the nominal channel thickness decreases from 0.2 to $0.1 \mathrm{~mm}$.

\subsection{Analysis of the aluminum regenerators}

The aluminum regenerators are analyzed using measured plate spacing in order to compare the predicted performance to the measured performance in the passive regenerator test. In the experiment, commercial grade alu- 


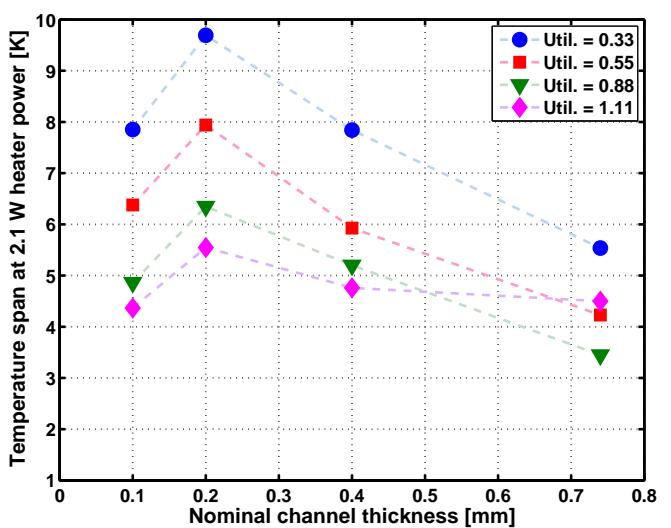

(a)

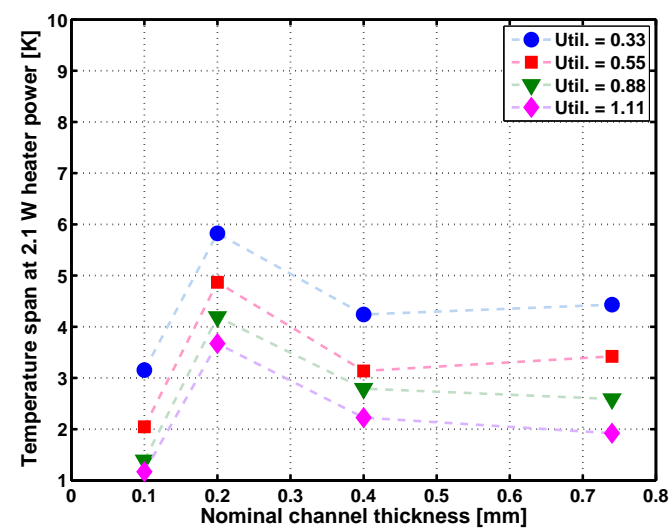

(b)

Figure 6: Steady-state temperature spans at a fixed heater power $(2.1 \mathrm{~W})$ as a function of mean channel thickness, thermal utilization and flow rate (a): $1.6 \mathrm{~mm}^{2} \mathrm{~s}^{-1},(\mathrm{~b}): 6.4$ $\mathrm{mm}^{2} \mathrm{~s}^{-1}$. The ambient temperature and thus the cold end was set to $288 \mathrm{~K}$.

Table III: Material properties used for simulation of the passive regenerator experiments.

\begin{tabular}{cc} 
Parameter & Value \\
\hline Plate specific heat & $902 \mathrm{~J} / \mathrm{kgK}$ \\
\hline Plate thermal conductivity & $218 \mathrm{~W} / \mathrm{mK}$ \\
\hline Plate density & $2700 \mathrm{~kg} / \mathrm{m}^{3}$ \\
\hline Fluid specific heat & $3811 \mathrm{~J} / \mathrm{kgK}$ \\
\hline Fluid thermal conductivity & $0.486 \mathrm{~W} / \mathrm{mK}^{3}$ \\
\hline Fluid density & $1031 \mathrm{~kg} / \mathrm{m}^{3}$ \\
\hline
\end{tabular}

minum and a mixture of $25 \%$ ethylene glycol and $75 \%$ water were used. The properties are given in Tab. III.

In Fig. 7 the effective heat transfer coefficient is plotted as a function of the mean (or nominal) channel thickness for face 2 (Fig. 7(a)) and face 1 (Fig. 7(b)) stacks at different flow rates. The effective heat transfer coefficient is seen to deviate drastically from the ideal case as the nominal channel thickness decreases (and thus the relative standard deviation increases). It 


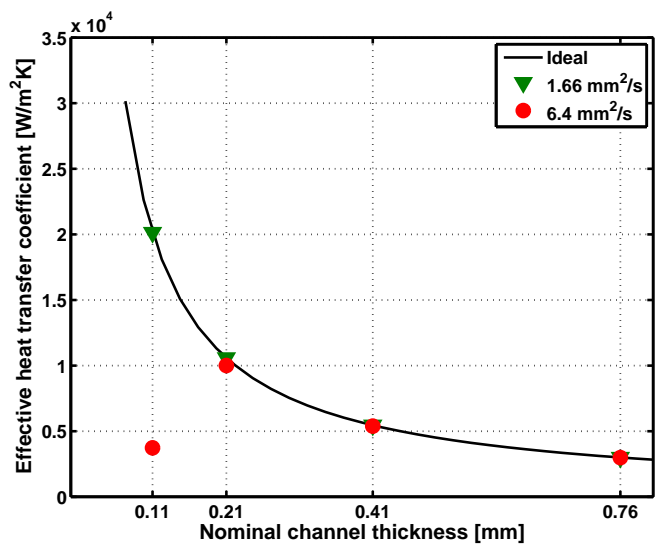

(a)

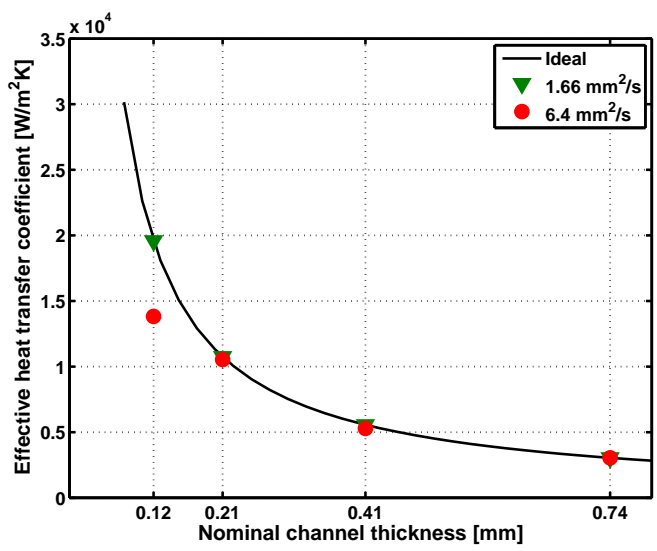

(b)

Figure 7: The predicted convective heat transfer coefficient as a function of nominal, i.e. mean, channel thickness for the face 2 stacks (a) and the face 1 stacks (b) at different flow rates. The heat transfer coefficient for a uniform ("ideal") plate stack is plotted for comparison. The flow rates are indicated in the figure legends.

is also apparent from the figure that the flow rate has a significant influence on the effective heat transfer coefficient. At the lowest flow rate almost no deviation from the ideal case is observed whereas at the larger flow rate the deviation becomes as much as a factor of four at the smallest nominal channel thickness.

At the higher experimental flow rate, the model is in very good agreement with experiment, which both predict that the $0.2 \mathrm{~mm}$ regenerator has the highest performance, the $0.1 \mathrm{~mm}$ and $0.4 \mathrm{~mm}$ stacks having similar performance, and the $0.7 \mathrm{~mm}$ stack having the lowest performance. The lower flow rate results do not agree as well with experiment. The model predicts that the $0.1 \mathrm{~mm}$ stack will have the highest performance, while the $0.2 \mathrm{~mm}$ stack exhibits the best performance experimentally. It was found that the solid thermal conductivity has an influence on heat transfer degradation, and 
the discrepancy between model and experiment may be partially caused by the commercial aluminum conductivity being lower than the value used in the model. However, assessing the sensitivity of model predictions to solid thermal conductivity is outside the scope of this paper.

\subsection{Plate stacks with constant standard deviation}

The analysis of the experimental regenerators is expanded to quantify the effect of reducing the plate spacing on heat transfer performance. 14 random numbers were chosen from a standard distribution with a mean of 0 and a standard deviation of 35. The numbers, shown in Tab. IV, are used to create a distribution of channel thicknesses. For each stack, the standard deviation is held constant at $35 \mu \mathrm{m}$ while the average thickness is varied. By keeping the deviations in channel thickness constant the effect of decreasing nominal plate spacing while using the same fabrication technique is simulated. In this section, pure aluminum properties and pure water properties as found in Tab. IV are used in the simulations.

Heat exchanger stacks comprised of 14 channels with nominal plate spacings from $0.075 \mathrm{~mm}$ to $0.8 \mathrm{~mm}$ with spacing distributions that are calculated using the deviation values from Tab. IV were simulated in the Comsol model for several fluid flow rates. The output curves were used to calculate the effective heat transfer coefficient in the regenerator by Eq. 15 and the results are shown in Fig. 8(a).

When considering the absolute heat transfer coefficient for the flow rates (Fig. 8(a)) it is observed that for the larger flow rate a certain value of the nominal channel thickness / relative standard deviation exists where the heat transfer coefficient has a maximum. At lower channel thicknesses the effective 
Table IV: The 14 normally distributed channels with a mean value of $0 \mathrm{~mm}$ and a standard deviation of $0.035 \mathrm{~mm}$.

\begin{tabular}{c|c} 
Channel no. & Deviation from nominal $[\mu \mathrm{m}]$ \\
\hline 1 & 6 \\
2 & -25 \\
3 & -3 \\
4 & 10 \\
5 & -27 \\
6 & -9 \\
7 & 11 \\
8 & -55 \\
9 & 31 \\
10 & 73 \\
11 & 29 \\
12 & -9 \\
13 & 13 \\
14 & -31 \\
\hline
\end{tabular}

heat transfer coefficient actually decreases. This is because as the nominal plate spacing decreases, the relative non-uniformity increases. At some value of plate spacing the heat transfer losses caused by non-uniformity effects become larger than the increase in heat transfer performance due to smaller nominal plate spacing. Figure 8(a) also shows that when the flow rate is low, the heat transfer performance is less affected by non-uniform plate spacing. This may be because the heat exchanger is dominated by conduction losses, which outweigh convection losses due to non-uniformity.

The ratio between pressure drop and heat transfer coefficient is commonly used as a measure of the quality of a particular heat exchanger geometry at a certain set of operating conditions. In Fig. 8(b) the pressure drop is seen to be reduced with a significantly smaller factor in the inhomogeneous stack 


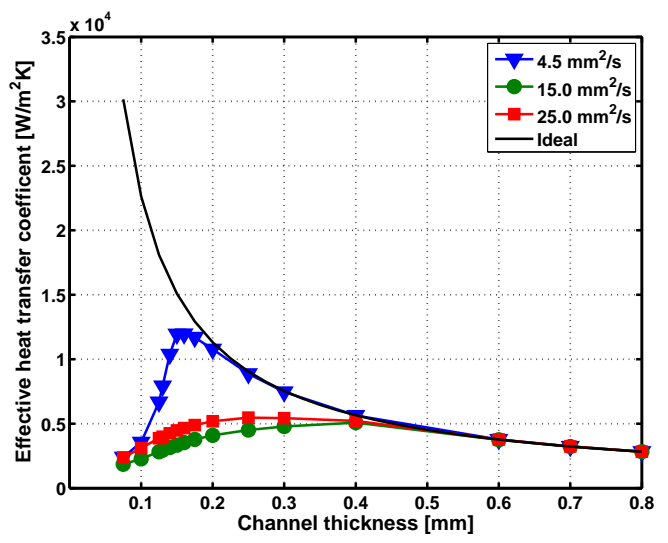

(a)

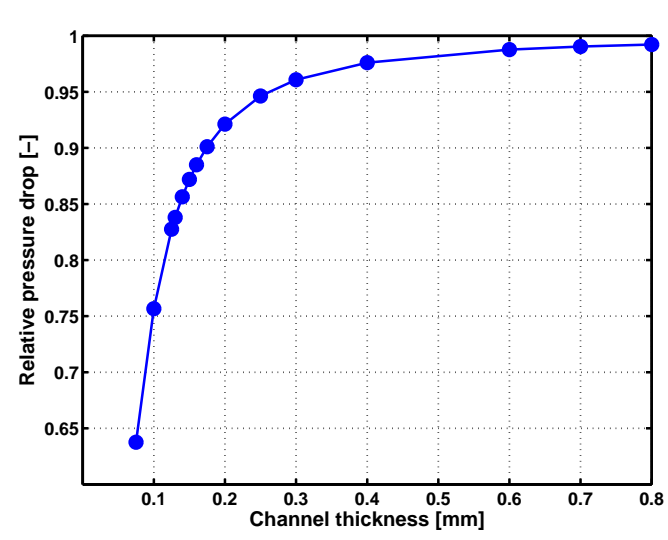

(b)

Figure 8: The effective heat transfer coefficient (a) and the relative pressure drop (b) both as a function of the nominal channel thickness compared to a uniform (ideal) stack. The relative standard deviation varies while the standard deviation is kept constant at 0.035 $\mathrm{mm}$. The relative pressure drop is calculated as the ratio between the pressure drop of the inhomogeneous stack and that of the equivalent homogeneous stack with a channel spacing equal to the mean spacing of the inhomogeneous stack.

than the heat transfer coefficient is. Although the ratio of the pressure drop in the non-uniform stack to that in the uniformly spaced stack does decrease as the nominal channel thickness decreases (due to the fact that individual channels in the distribution become relatively large) the decrease is clearly smaller than those of the effective heat transfer coefficient, particularly at the larger flow rates. It may thus be concluded that not only does the heat transfer become significantly degraded as the channel thickness decreases, but the pressure drop still remains relatively large. Thus with increasing relative non-uniformity, both a severe reduction in heat transfer coefficient is observed at the same time as the quality parameter (heat transfer / pressure drop fraction) is significantly decreased. 


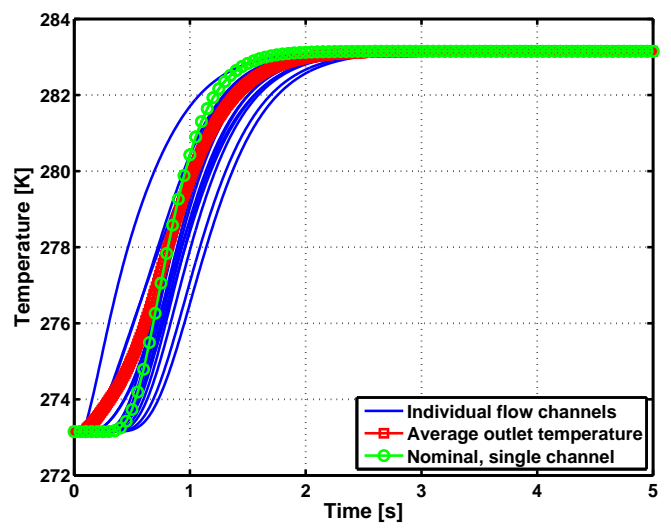

(a)

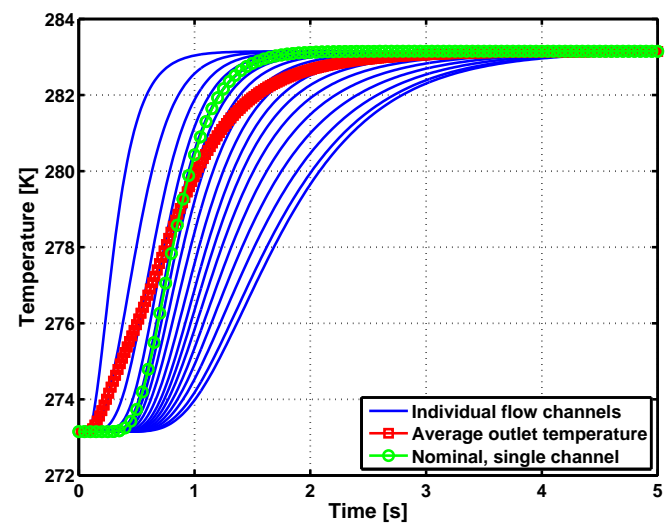

(b)

Figure 9: Examples of the breakthrough curves of the individual channels in the $0.1 \mathrm{~mm}$ (face 2) stack unsorted (a) and sorted (b). Overplotted are the resulting breakthrough curves for each stack (as calculated using Eq. 10) and the single channel breakthrough curve found by applying the mean (nominal) spacings of the respective stacks.

\subsection{Influence of thermal cross-talk}

The flow maldistribution in an inhomogeneous parallel plate stack causes what may be denoted thermal cross talk. The thermal waves of each individual channel will propagate at different speeds due to the different fluid velocities. Heat transfer will therefore be present orthogonal to the direction of the flow through the solid. The significance of this effect is of course dependent on the actual materials properties as well as the degree of flow maldistribution.

The $0.1 \mathrm{~mm}$ (face 2) and $0.7 \mathrm{~mm}$ (face 2) stacks are modeled in two ways. In the first they are run with the channel heights arranged in the same order as the actual plate stack at a flow rate of $15 \mathrm{~mm}^{2} \mathrm{~s}^{-1}$ whereas in the other way their individual channels are sorted after size. In this way the cross talk will differ between the two setups, keeping everything else the same. The high flow rate is chosen to reduce the relative effect of conduction. 
Table V: M and $\mathrm{S}$ values for the $0.1 \mathrm{~mm}$ (face 2) and $0.7 \mathrm{~mm}$ (face 2) stacks both for the original stacks and when they are sorted. Furthermore, the single channel corresponding values are provided.

\begin{tabular}{c|cccccc} 
& $0.1(2)$, sorted & $0.1(2)$ & 0.1 single & $0.7(2)$, sorted & $0.7(2)$ & 0.7 single \\
\hline $\mathrm{S}[\mathrm{s}]$ & 0.86 & 0.69 & 0.45 & 1.37 & 1.36 & 1.30 \\
\hline $\mathrm{M}[\mathrm{K} / \mathrm{s}]$ & 8.4 & 10.35 & 15.75 & 5.83 & 5.88 & 6.26 \\
\hline \hline
\end{tabular}

Considering Fig. 9 the difference between the two different approaches for the $0.1 \mathrm{~mm}$ (face 2) stack are clearly observed. The resulting outlet temperature curve is plotted as are each of the individual channel outputs. Furthermore, the nominal (single channel) output curve is overlayed for comparison. The average output curve of the sorted stack (Fig. 9(b)) does breaks through sooner than that of the unsorted stack (Fig. 9(a)). However, it is clearly seen that both the steepest part of the curve and the time interval between the $20 \%$ and $80 \%$ breakthroughs indicate a poorer performance than that of the unsorted stack. In Table $\mathrm{V}$ the $\mathrm{M}$ and $\mathrm{S}$ values are given.

In the case of the sorted stack the individual channels behave more closely to being individually isolated channels than in the case of the unsorted stack. In this way the majority of the channels have breakthroughs that are significantly slower in the case of the sorted stack compared to the case of the unsorted stack. This means that the resulting average breakthrough curve is extended. In terms of the thermal cross talk this means that the unsorted, or random, stack overall experiences more cross talk than the sorted stack does. In that way the stack that is non-ideal may be helped somewhat in terms of the cross talk that seems to smooth out the effect of the flow maldistribution.

In Fig. 10 the breakthrough curves for the $0.7 \mathrm{~mm}$ (face 2) stack in both 


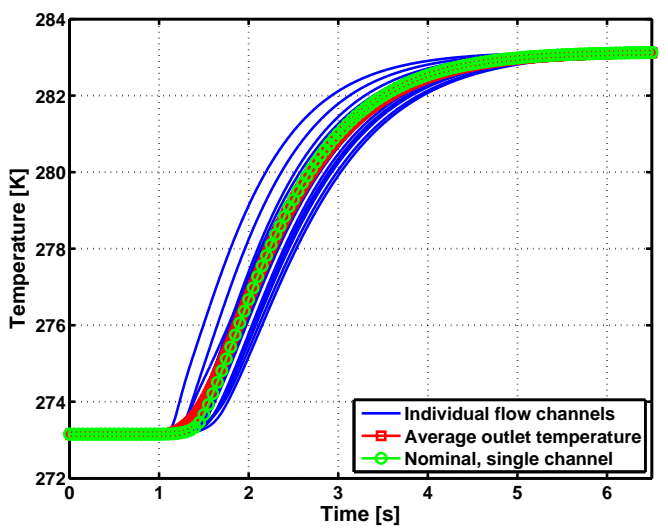

(a)

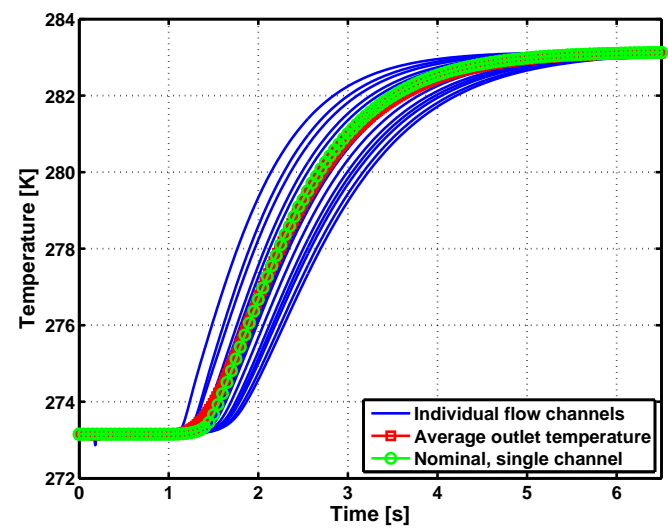

(b)

Figure 10: Breakthrough curves of the $0.755 \mathrm{~mm}$ (face 2) of the individual flow channels unsorted (a) and sorted (b). As in Fig. 9, the resulting breakthrough curves of the overall stacks and the single channel breakthrough curves are plotted.

the unsorted and sorted modes are plotted in the same manner as Fig. 9 where the $0.1 \mathrm{~mm}$ (face 2) stack was considered. The trend is the same as for the nominally smaller channel thickness stack, however, the effect of sorting the channels is significantly smaller (see Tab. V). This is simply due to the fact that the thermal waves moving perpendicular to the direction of the flow are exposed to a much larger thermal resistance since the flow channels are roughly seven times larger than in the former case.

A direct comparison of the influence of the thermal cross talk may be done by considering Fig. 11. Here, the breakthrough curves of the two extreme channels from the $0.1 \mathrm{~mm}$ (face 2) stack are plotted for the two modes (unsorted and sorted). In the same figure the corresponding nominal breakthrough curves are plotted. It is clearly observed that the thermal cross talk is more pronounced in the unsorted stack. The effect is that the individual extreme breakthrough curves are brought closer together and thus 


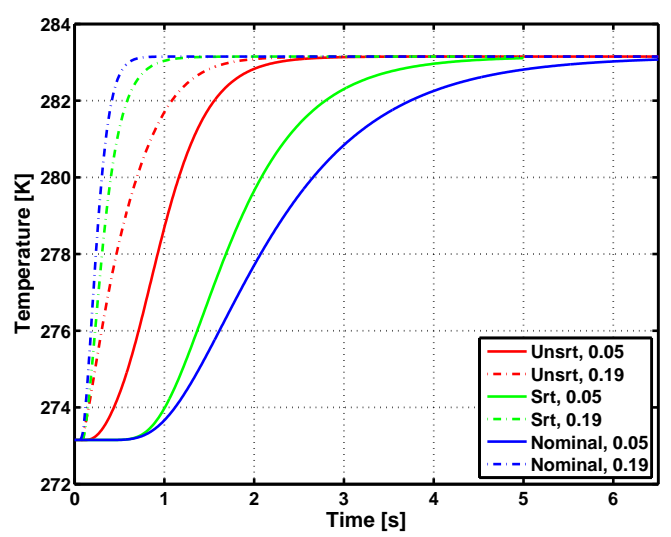

Figure 11: The breakthrough curves of the two extreme channels from the $0.1 \mathrm{~mm}$ (face 2 ) stack plotted for both the unsorted and sorted modes. The nominal curves indicate the corresponding single channel heat exchangers with the same fluid velocity as present in the respective channels in the stacks. The thicknesses of the two channels are 0.05 and $0.19 \mathrm{~mm}$, respectively.

further from their respective nominal curves.

\section{Conclusions}

This paper presents a numerical method to quantify the heat transfer degradation associated with non-uniform flow channel thickness in a twodimensional stack of flat plates using a single blow technique to characterize bulk heat transfer in the heat exchanger. The resulting heat transfer degradation can then be used in a simpler $1 \mathrm{D}$ or single-channel $2 \mathrm{D}$ model to model more complex systems using microchannel heat exchangers. Simulations showed that large decreases in heat transfer performance can occur when flow channels are not uniformly spaced, which may explain the lowerthan-expected performance of microchannel heat exchangers reported in the literature. These effects are unrelated to many previous explanations of reduced microchannel performance, such as break-down of the continuum fluid 
assumption and temperature dependent properties in the fluid. The CFD model presented was qualitatively validated on flat plate heat exchangers tested as passive regenerators. The model predicted that as the channel spacing was decreased using a given fabrication technique, the gap between the ideal and actual heat transfer performance increases with decreasing plate spacing, which was observed experimentally in a cyclic steady-state test apparatus.

This paper also studied the effects of thermal cross talk between fluid channels. The cross talk was shown to improve performance of a microchannel heat exchanger compared to a series of fluid channels that are thermally isolated from each other. The range of channel thickness affects microchannel performance, but the arrangement of the various channel thicknesses can also be important. Results in this paper are presented only for heat exchangers consisting of aluminum and a water-based heat transfer fluid. Results for materials with different properties may vary by a large degree and should be considered individually.

\section{Acknowledgements}

The authors thank the support of the Programme Commission on Energy and Environment (EnMi) (Contract no. 2104-06-0032) which is part of the Danish Council for Strategic Research. The technical assistance from Johan Hjelm, Risø DTU, is gratefully appreciated. K.K. Nielsen also wishes to thank The Danish Council for Independent Research - Technology and Production Sciences (Contract no. 10-092791) for financial support. 


\section{References}

[1] R. Radebaugh. Development of the pulse tube refrigerator as an efficient and reliable cryocooler. Proc. Institute of Refrigeration, 96:11-31, 19992000.

[2] M. J. White, G. F. Nellis, S. A. Klein, and Y. Zhu, W. Gianchandani. An experimentally validated numerical modeling technique for perforated plate heat exchangers. J. Heat Transfer, 132:111801, 2010.

[3] S. Jain, P.L. Dhar, and S.C. Kaushik. Evaluation of liquid dessicant based evaporative cooling cycles for typical hot and humid climates. Heat recovery systems \& CHP, 14(6):621-632, 1994.

[4] R. W. Dyson, S. D. Wilson, and R. C. Tew. Review of computational stirling analysis methods. Collect. Tech. Pap. Int. Energy Convers. Eng. Conf., 1:511-531, 2004.

[5] B. Kongtragool and S. Wongwises. A review of solar-powered stirling engines and low temperature differential stirling engines. Renewable $\mathcal{E}$ Sustainable Energy Reviews, 7(2):131-154, 2003.

[6] R. J. McGlen, R. Jachuck, and S. Lin. Integrated thermal management techniques for high power electronic devices. Applied Thermal Engineering, 24(8-9):1143-1156, 2004.

[7] K.A. Gschneidner and V.K. Pecharsky. Thirty years of near room temperature magnetic cooling: Where we are today and future prospects. International Journal of Refrigeration, 31:945-961, 2008. 
[8] M. P. MItchell, D. Gedeon, G. Wood, and M. Ibrahim. Results of tests of etched foil regenerator material. In Cryocoolers, volume 14, pages 381-387, 2007.

[9] P. Rosa, T.G. Karayiannis, and M.W. Collins. Single-phase heat transfer in microchannels: The importance of scaling effects. Applied Thermal Engineering, 29(17-18):3447-3468, 2009.

[10] G. L. Morini. Scaling effects for liquid flows in microchannels. Heat Transfer Eng, 27(4):64-73, 2006.

[11] A. G. Fedorov and R. Viskanta. Three-dimensional conjugate heat transfer in the microchannel heat sink for electronic packaging. International Journal of Heat and Mass Transfer, 43(3):399-415, 2000.

[12] G. Croce and P. D'Agaro. Numerical analysis of roughness effect on microtube heat transfer. Superlattices and Microstructures, 35(3-6):601616, 2004.

[13] G. Croce and P. D'Agaro. Numerical simulation of roughness effect on microchannel heat transfer and pressure drop in laminar flow. J. Phys. D: Appl. Phys., 38(10):1518-1530, 2005.

[14] J. Koo and C. Kleinstreuer. Analysis of surface roughness effects on heat transfer in micro-conduits. International Journal of Heat and Mass Transfer, 48(13):2625-2634, 2005.

[15] P. S. Lee, S. V. Garimella, and D. Liu. Investigation of heat transfer in rectangular microchannels. International Journal of Heat and Mass Transfer, 48(9):1688-1704, 2005. 
[16] G. Gamrat, M. Favre-Marinet, and D. Asendrych. Conduction and entrance effects on laminar liquid flow and heat transfer in rectangular microchannels. International Journal of Heat and Mass Transfer, 48(14):2943-2954, 2005.

[17] W. Qu and I. Mudawar. Analysis of three-dimensional heat transfer in micro-channel heat sinks. International Journal of Heat and Mass Transfer, 45(19):3973-3985, 2002.

[18] J.H. Ryu, D.H. Choi, and S.J. Kim. Three-dimensional numerical optimization of a manifold microchannel heat sink. International Journal of Heat and Mass Transfer, 46(9):1553-1562, 2003.

[19] W. Brix, M. R. Kærn, and B. Elmegaard. Modelling refrigerant distribution in microchannel evaporators. International Journal of Refrigeration, 32(7):1736-1743, 2009.

[20] W. Brix, M. R. Kærn, and B. Elmegaard. Modelling distribution of evaporating $\mathrm{CO}_{2}$ in parallel minichannels. International Journal of Refrigeration, 33(6):1086-1094, 2010.

[21] E. U. Schlunder. Mechanism of mass-transfer in heterogeneous systems in particular in fixed-beds, fluidized-beds and on bubble trays. Chemical Engineering Science, 32(8):845-851, 1977.

[22] M. Martin, C. Patton, J. Schmitt, and S. V. Apte. Direct simulation based model-predictive control of flow maldistribution in parallel microchannels. Journal of Fluids Engineering, Transactions of the ASME, 131(11):1112011-11120117, 2009. 
[23] J. B. Jensen, K. Engelbrecht, C. R. H. Bahl, N. Pryds, G. F. Nellis, S. A. Klein, and B. Elmegaard. Modeling of parallel-plate regenerators with non-uniform plate distributions. International Journal of Heat and Mass Transfer, 53(23-24):5065-5072, 2010.

[24] J. B. Jensen, C. R. H. Bahl, K. Engelbrecht, B. Elmegaard, and N Pryds. Analysis of single blow effectiveness in non-uniform parallel plate regenerators. International Journal of Heat and Mass Transfer, 54(2122):4746-4751, 2011.

[25] K. Engelbrecht, K. K. Nielsen, and N. Pryds. An experimental study of passive regenerator geometries. In P. W. Egolf, editor, Fourth International Conference on Magnetic Refrigeration at Room Temperature. International Institute of Refrigeration, 2010.

[26] K. Engelbrecht, C.R.H. Bahl, and K.K. Nielsen. Experimental results for a magnetic refrigerator using three different types of magnetocaloric material regenerators. International Journal of Refrigeration, 34(4):11321140, 2011.

[27] C. R. H. Bahl, T. F. Petersen, N. Pryds, and A. Smith. A versatile magnetic refrigeration test device. Review of Scientific Instruments, 79(9):093906, 2008.

[28] G. D. Dragutinovic and B. S. Baclic. Operation of Counterflow Regenerators, volume 4 of International Series on Developments in Heat Transfer. Computational Mechanics Publications, 1 edition, 1998. 
[29] J.D. Jones. Optimization of stirling engine regenerator design. Proceedings of the 25th Intersociety Energy Conversion Engineering Conference, pages 359-65 vol.5, 1990.

[30] Poh-Seng Lee and Suresh V. Garimella. Thermally developing flow and heat transfer in rectangular microchannels of different aspect ratios. International Journal of Heat and Mass Transfer, 49(17-18):3060-3067, 2006.

[31] G. Maranzana, I. Perry, and D. Maillet. Mini- and micro-channels: influence of axial conduction in the walls. International Journal of Heat and Mass Transfer, 47(17-18):3993-4004, 2004.

[32] Comsol. Comsol Multiphysics Model Library, third ed. COMSOL AB, Chalmers Teknikpark 41288 G., 2005.

[33] R. W. Fox and A. T. McDonald. Introduction to Fluid Mechanics. John Wiley and Sons, Inc., 1994.

[34] P.J. Heggs and D. Burns. Single-blow experimental prediction of heat transfer coefficients - a comparison of four commonly used techniques. Experimental Thermal and Fluid Science, 1(3):243-251, 1988.

[35] K. Engelbrecht. A Numerical Model of an Active Magnetic Regenerator Refrigerator with Experimental Validation. PhD thesis, University of Wisconsin, Madison, 2008.

[36] M. Nickolay and H. Martin. Improved approximation for the Nusselt number for hydrodynamically developed laminar flow between parallel 
plates. International Journal of Heat and Mass Transfer, 45(15):3263$3266,2002$.

[37] F. P. Incropera, D. P. Dewitt, T. L. Bergman, and A. S. Lavine. Fundamentals of Heat and Mass Transfer. John Wiley \& Sons, 6th edition, 2007.

Appendix A. Resulting laser measurements of the regenerator stacks 


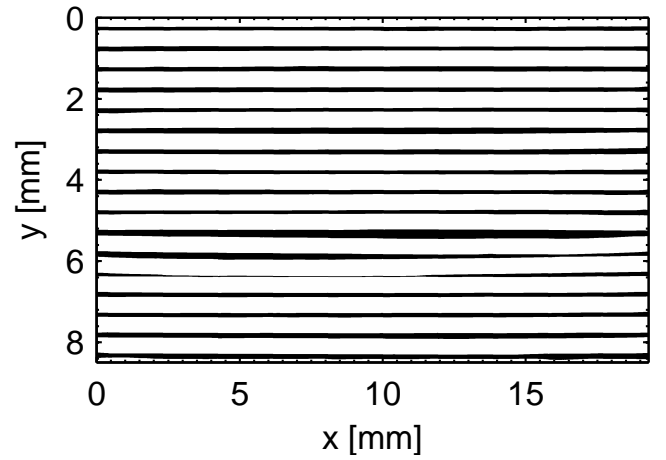

(a) $0.1 \mathrm{~mm}$, face 1

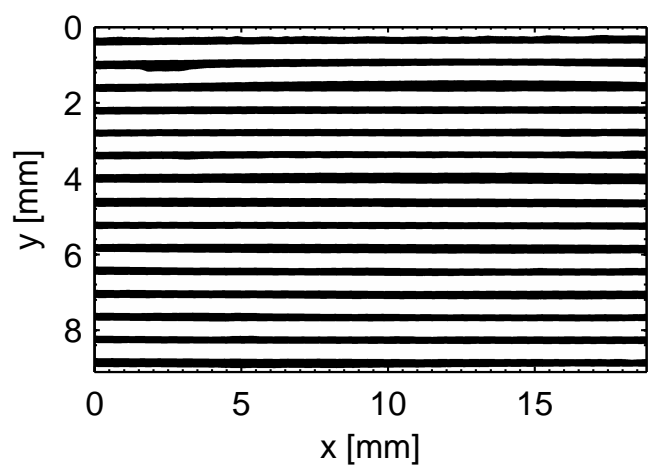

(c) $0.2 \mathrm{~mm}$, face 1

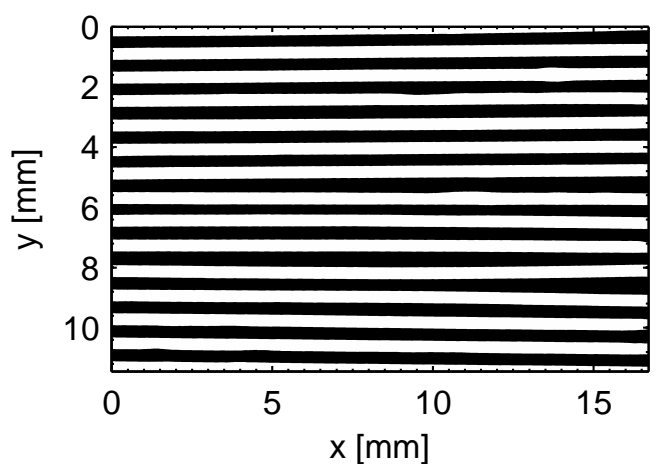

(e) $0.4 \mathrm{~mm}$, face 1

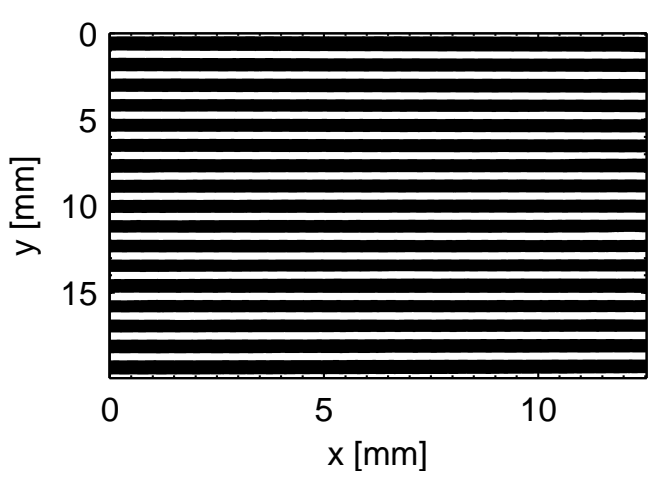

(g) $0.7 \mathrm{~mm}$, face 1

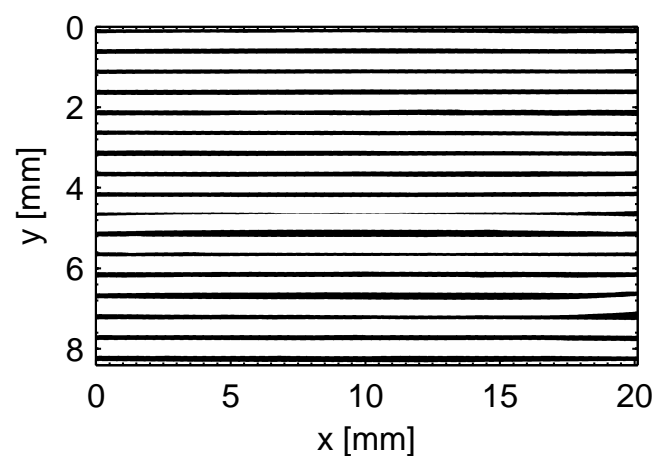

(b) $0.1 \mathrm{~mm}$, face 2

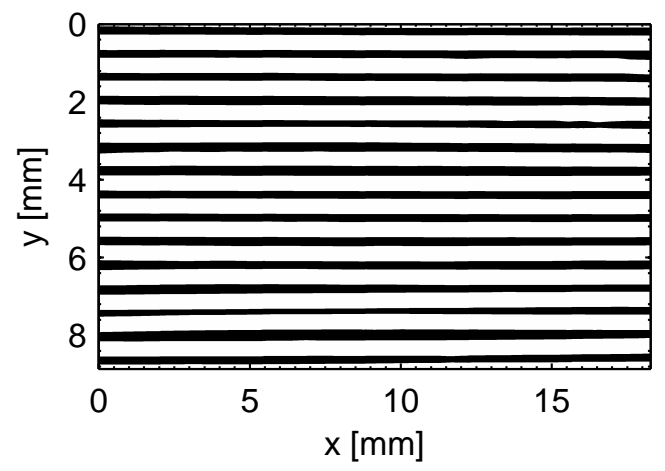

(d) $0.2 \mathrm{~mm}$, face 2

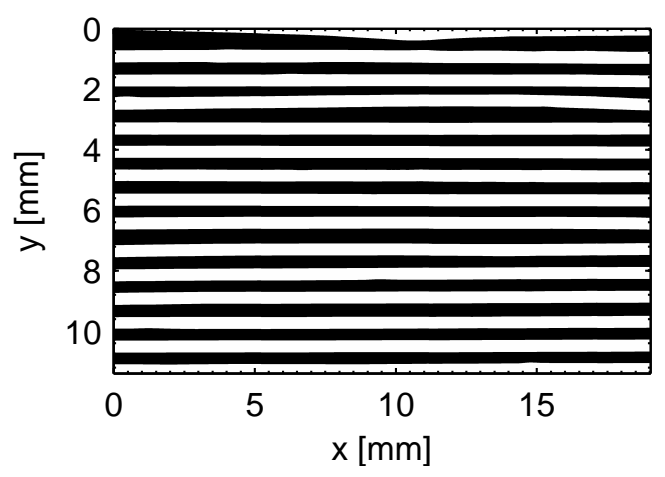

(f) $0.4 \mathrm{~mm}$, face 2

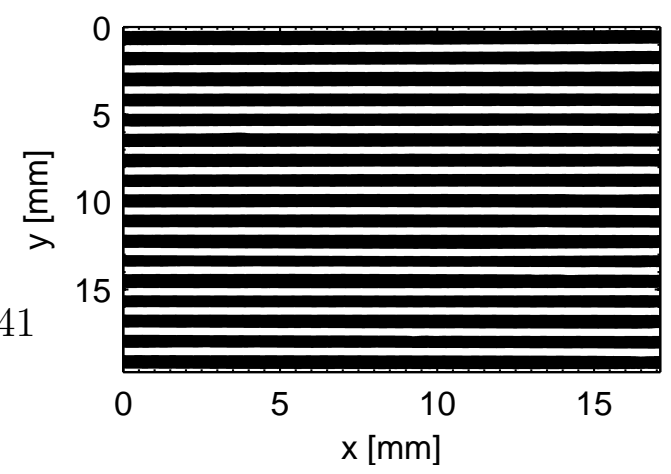

(h) $0.7 \mathrm{~mm}$, face 2

Figure A.12: The laser-measured cross sections of each of the eight regenerators considered. The mean plate spacings and the labels (face 1 and face 2, respectively) are indicated in the sub-figure captions. White indicates solid plates and black is the void space between the plates. 